\title{
Teachers' Perception of Prevalence and Forms of Violence in Early Childhood Classes in Delta State of Nigeria
}

\author{
Grace 0. Akpochafo \\ Department of Guidance and Counseling, Faculty of Education, \\ Delta state university, Abraka, Nigeria \\ Email Address: omejevwel@yahoo.com
}

\section{Doi:10.5901/jesr.2014.v4n3p469}

\begin{abstract}
This paper examines teachers' perception of prevalence and forms of violence in early childhood classes. Its theoretical basis was conceptualized on the behavioural theory which stresses that behaviour is a function of the person and his environment. Violence is one of the greatest social problems facing Nigeria and the entire globe. Most times, people view it as an act exhibited by only youths and adults. But the violence we see today, the seeds must have been sown in the formative years. It therefore becomes pertinent to investigate violence in early childhood classes. The study is guided by two research questions and one hypothesis. It employs a descriptive survey design. The population for the study comprised all primary school teachers in Delta State. A sample of one hundred and twenty teachers teaching in early childhood classes was drawn using the simple random sampling technique from both urban and rural areas. The instrument used was the questionnaire titled "Prevalence and Forms of Violence (PFV)". Cronbach alpha which yielded a coefficient index of 0.77 was used for the reliability. The data gathered were analyzed using mean and t-test. From the analysis, it was revealed that shouting, noise making, fighting, verbal abuse, slapping, tearing pupil's books, hitting, beating were more prevalent in early childhood classes. It was therefore recommended among others that parents and teachers should strive to be good role models and that parents should learn to minimize conflicts in the home. Curriculum planners should endeavour to do relevant curriculum to stem violence.
\end{abstract}

Keywords: Perception, Prevalence, Violence and Early Childhood

\section{Introduction}

Early childhood education refers to the education of young children from birth through age eight. These years cover the nursery years and primaries one to three. The early years in a child's life are very crucial as they lay the foundation for life-long learning. Rutter, Giller and Hagell (1998); Tremblay (1999). Bush (2001) see the early years as the foundation upon which successful lives are built. There is no gainsaying that they are the formation period when development is most accelerated. These years "have a long reaching" effect for behaviour especially anti-social behaviour, delinquency and crime.

Early childhood education is supposed to provide education that will make children morally upright in the society and be non-violent. One can then ask: Are Nigerian children receiving this type of education? Are the classrooms free of violence? What are the forms of violence in early childhood classes? How prevalent is violence in the early childhood classes? These are the questions this paper addressed.

There are different definitions of violence. The World Health Organization (WHO), (1996) defines violence as the intentional use of physical force or power, threatened or actual, against oneself, another person or against a group or community that either results in or has a high likelihood of resulting in injury, death, psychological harm, maldevelopment or deprivation. Olweus (1999) in his definition of violence also confines it to the use of physical force. He defines violence/violent behaviour as aggressive behaviour where the actor or perpetrator uses his or her own body or an object (including a weapon) to inflict (relatively serious) injury or discomfort upon an individual. From these definitions it can be seen that violence is threatening, harmful and is intentional.

In Nigeria, violence has reached an alarming stage. Violence is one of the greatest social problems facing Nigeria and according to Radojkovic (2007) it is a phenomenon that we can see frequently in our society. Violence is at times seen as something that is perpetrated by only youths and adults. But the violence acts one sees today have their beginnings in the formative years. It therefore becomes pertinent that violence in early childhood age should be investigated. Espelage, Holt and Henkel (2003), Kondrasuk, Greene, Wagoner, Edwards and Nayak-Rhodes (2005) are of the view that school violence has remained a national concern for schools and communities across the country. 
Chukwu (2003) observe that violence is prevalent in the primary schools which are the foundation level of our educational system. There is increase in the various types of violent behaviour in the classrooms and invariably in the Nigerian school system. Yarpuzlu, Karatas, Kilic (2010) asserts that school violence have grown in number and appeared in higher frequencies. Osanyi (2001) reported the study of a group of care givers at a workshop training in Lagos state and they described the behaviour of the children in their care as stubborn, rude, aggressive, obstinate and destructive. Osanyi (2007) in another study examined forms of violence among preschool children and discovered that about $94 \%$ and $91 \%$ of the respondents indicated shouting and hitting/slapping/beating as the symptoms of violence. The respondents suggested parents as being responsible for these acts as some instruct their children to fight back if any one tries any violent acts on them. In a study carried out by African Child Policy Forum (2010), it was reported that beating accounted for $90 \%$ of the forms of physical violence in Nigeria, $83 \%$ in Senegal and $79 \%$ in Cameroun. This was followed by hitting which recorded $91 \%$ in Burkina Faso, $84 \%$ in Nigeria, 74\% in Democratic Republic of Congo, 52\% in Senegal and $43 \%$ in Cameroun.

From History learning site on classroom violence 2012, the figures released by the Department of Education covering the academic calendar of 2010/2011 shows that teachers and pupils are experiencing violence on a daily basis throughout the United Kingdom as 6,390 children of primary age were suspended for verbal abuse, 10,000 primary aged children were equally suspended for persistent disruption during classes. In the Guardian 2008, it was reported that, a five year old smuggled knife into school intending to attack a teacher so he could move class. Martin (2013) report of rise of violent primary pupils and asserts that 40 teachers were attacked everyday - more than at secondary schools. He went further to say that official statistics shows that 8,030 pupils age 5 to 11 received sanction in 2010/2011 - a 15\% rise over four years. Violence exists in both rural and urban areas. RAND 2013 asserts that school violence is not confined to urban schools but that it is also prevalent in suburban schools. Yörük and Cankaya (2013) in the study trying to find out the thoughts of teachers working in rural and urban areas about students' violent behaviours discovered that primary school students in rural areas exhibited more violent behaviours than those in urban areas.

These initial experiences of violent acts have influences on other kinds of violence behaviour in later life. Lasford, Dodge, Petit, Bates, Crozier, Kaplow 2002 found out that children who were physically abused prior to kindergarten were rated by their mothers as being almost twice as aggressive as their non abused counterparts. In another study, Lansford, Miller-Johnson, Berlin, Dodge, Bates, Petit, (2007) also discovered that physical abuse lead not only to later violent delinquency but also more global pattern of violent and non-violent dysfunction.

Furthermore, initial verbal abuse from the works of Effects of Emotional abuse leads to insecurity, poor self esteem, destructive behaviour, angry acts such as fire setting, withdrawal, alcohol or drug abuse, suicide and difficulty in forming relationship can also be possible results of emotional abuse. It also results in other more serious psychological and or behaviour problems-depression.

The theoretical framework of this paper is based on Behavioural theory which posits that all human behaviour is learned through interaction with the social environment. It means that behaviour is a function of the person and his environment $B=F(P+E)$. These behavioural theorists maintain that people are not born with violent disposition but that they learn to think and act violently as a result of their day to day experiences (Bandura, 1977). Bartol (2002) opined that studies have shown that people who live in violent communities learn to model the behaviour of their neighbours. This theory stresses on four factors which help to produce violence according to Ministry of children and youth services namely: threat, learnt aggressive skills by observing others, belief of reward for violence and a system that condones violent acts. The behavioural view of human nature emphasizes that at birth the infant has a neutral character which cannot be said to be good or bad, behaviour is learnt, behaviour can be modified and the environment influences behaviour. This framework no doubt provides parents, teachers and counselor a crucial tool for the management of violence in early childhood.

This study sets to examine teachers' perception of violence in early childhood classes since it is teachers that can report about the violent situations of their pupils. Furthermore, the study will look at location; if teachers perceived violence to be more prevalent in rural or urban areas.

To guide the study, two research questions were asked and one hypothesis formulated as follows:

1. What are teachers' perceptions of the prevalence of violence in the early childhood classes?

2. Is there any difference in the urban and rural teachers' perception of the prevalence of violence in the early childhood classes?

3. Is there any significant difference between the perception of teachers from urban and rural areas as to the prevalence of violence in early childhood classes? 


\section{Methodology}

This study employs a descriptive survey type, design to investigate the forms and prevalence of violence in early childhood classes.

The population of the study comprised all primary school teachers in Delta State. From the target population one hundred and twenty teachers teaching early childhood classes were selected using the simple random sampling technique from both urban and rural areas. The sample was made up of seventy-two (72) urban teachers and forty-eight (48) rural teachers. An instrument titled Prevalence and Forms of Violence (PFV) was used to collect information from the respondents. The instrument was made up of two sections namely $A$ and $B$. Section A was made up of respondents bio-data and section $B$ consisted of sixteen (16) items showing forms of violence in the classroom. A six-point scale was used for the instrument ranging from 5 to 0 . If a respondent ticks 5 it means the prevalence of that item is very high and 0 means it does not exist. The benchmark for acceptance is 2.50 , that is, $5+4+3+2+1+0=15 \div 6=2.50$.

The reliability of the instrument was ascertained by using Cronbach alpha which yielded a co-efficient index of 0.77. This indicated that the instrument was fit for use. The instrument was also shown to Measurement and Evaluation experts in the Department of Guidance and Counselling for face and content validity. Their input was taken into consideration and they equally ascertained that the instrument measures what it is supposed to measure. Percentages and mean were used to analyze research questions while t-test was used to test the hypothesis at .05 level of significance.

\subsection{Research Question I:}

What are teachers' perception of the forms and prevalence of violence in the early childhood classes? This question was answered by using mean ranking. This analysis is shown in the table below.

Table 1: Mean ranking of teachers' perception of the prevalence and forms of violence in the early childhood classes

\begin{tabular}{clcc}
\hline S/N & N = 120 Forms of violence in classroom & Mean & Mean Ranking \\
\hline 1 & Shouting & 3.93 & 1 \\
2 & Hitting & 2.67 & 7 \\
3 & Slapping & 2.80 & 5 \\
4 & Beating & 2.53 & 8 \\
5 & Playing with toy guns & 0.13 & 16 \\
6 & Playing with daggers and video games & 0.33 & 15 \\
7 & Tearing of pupils' books & 2.73 & 6 \\
8 & Mutilating pupils book & 2.40 & 9 \\
9 & Fighting & 3.20 & 3 \\
10 & Intimidation & 1.20 & 11 \\
11 & Verbal abuse & 2.93 & 4 \\
12 & Gang violence & 1.33 & 10 \\
13 & Noise making & 3.73 & 2 \\
14 & Being rude to teachers & 1.00 & 12 \\
15 & Deliberately distracting others & 0.87 & 13 \\
16 & Humiliations & 0.73 & 14 \\
\hline
\end{tabular}

Table 1 shows teachers' perception of the prevalence of violence in the early childhood classes. The mean ranking indicates the most frequent occurring prevalence of violence in the early childhood classes as follows: shouting, noise making, fighting, verbal abuse, slapping, tearing of peoples book, hitting, beating, mutilating pupils book, gang violence, intimidation, being rude to teachers, deliberately distracting others, humiliations, playing with daggers and video games and playing with toy guns.

\subsection{Research Question 2:}

Is there any difference in urban and rural teachers' perception of the prevalence of violence in the early childhood classes? 
Table 2: Percentage responses of urban and rural teachers' perception of the prevalence of violence in the early childhood classes.

\begin{tabular}{clcccc}
\hline \multirow{2}{*}{ S/N } & \multirow{2}{*}{ Forms of Violence } & \multicolumn{2}{c}{$\begin{array}{c}\mathbf{N}=\mathbf{7 2} \\
\mathbf{N}=\mathbf{4 8}\end{array}$} \\
& & Percentage & \multicolumn{2}{c}{ (\%) Urban Teachers } & Percentage (\%) Urban Teachers \\
\cline { 3 - 5 } & & Agreed & Disagreed & Agreed & Disagreed \\
\hline 1 & Shouting & 94.4 & 5.6 & 91.7 & 8.3 \\
2 & Hitting & 72.2 & 27.8 & 75 & 25 \\
3 & Slapping & 72.2 & 27.8 & 75 & 25 \\
4 & Beating & 61.1 & 38.9 & 58.3 & 41.7 \\
5 & Playing with toy guns & 0 & 100 & 0 & 100 \\
6 & Playing with daggers and video games & 0 & 100 & 0 & 100 \\
7 & Tearing of pupils book & 66.7 & 33.3 & 83.3 & 16.7 \\
8 & Mutilating pupils book & 55.6 & 44.4 & 66.7 & 33.3 \\
9 & Fighting & 77.8 & 22.2 & 83.3 & 16.7 \\
10 & Intimidation & 16.7 & 83.3 & 25 & 75 \\
11 & Verbal abuse & 77.8 & 22.2 & 83.3 & 16.7 \\
12 & Gang violence & 16.7 & 83.3 & 16.7 & 83.3 \\
13 & Noise making & 29.2 & 70.8 & 83.3 & 16.7 \\
14 & Being rude to teachers & 11.1 & 88.9 & 0 & 100 \\
15 & Deliberately distracting others & 0 & 100 & 0 & 100 \\
16 & Humiliations & 0 & 100 & 0 & 100 \\
\hline
\end{tabular}

The results in table 2 shows little or no difference in urban and rural teachers' perception of violence in early childhood classes. This result is further seen in answer to hypothesis one shown below.

\subsection{Hypothesis}

Is there any significant difference in the urban and rural teachers' perception of the prevalence of violence in the early childhood classes?

Table 3: t-test analysis of urban and rural teachers' perception of the prevalence of violence in early childhood classes.

\begin{tabular}{cccccccccc}
\hline Respondent & N & Mean & SD & df & t-cal & Sign. & MD & Upper bound & Lower bound \\
\hline Urban & 72 & 30.56 & 9.05 & & & & & & \\
Rural & 48 & 29.25 & 6.71 & 118 & .855 & .040 & 1.31 & 4.329 & -1.718 \\
\hline
\end{tabular}

As shown in table 3 , the computed t-value of .855 was found not to be significant at $d f=118, p>0.05$ level. Therefore the null hypothesis was accepted. This implies that there is no significant difference between urban and rural teachers' perception of the prevalence of violence in the early childhood classes. The conclusion was drawn that there is no difference in the perception of urban and rural teachers.

Furthermore as shown in table 3 , the urban teachers: $n=72$ with a mean $(M)$ value of $30.56, S D=9.05$, has a mean difference of 1.31 over their rural counterparts that has a mean of $29.25, \mathrm{SD}=6.71$. The mean difference (MD) of $1.31, P>.05$ alpha level that lies between the upper limits bound and lower limits bound was not found to be statistically significant at $95 \%$ confidence interval $(\mathrm{Cl})$. The conclusion is drawn that the effect size of 1.31 which was in the favour of urban teachers indicate that there is no significant difference between the rural teachers on perception of prevalence of violence in the early childhood.

\section{Discussion of Findings}

This study has shown teachers' perception of prevalence and forms of violence in early childhood classes. Some prevalent forms like shouting, slapping, beating, hitting are not surprising as it agrees with Osanyin (2007), ACPF (2010) findings while verbal abuse agrees with the figures released in 2012 in the United Kingdom (Wikipedia, 2013). The study also revealed other forms of prevalence of violence like noise making, fighting and tearing of pupils' books which cannot be taking lightly. If these forms of violence are not checked at this age it could lead to other violent reactions in future. 
Studies abound that early years are crucial and lay the foundation for later years.

The findings from the hypothesis reveal that there is no significant difference in teachers' perception of prevalence of violence in urban and rural areas. This implies that violence abound in rural and urban areas. This is in line with RAND 2013 assertion that school violence is not confined to urban schools but that it is prevalent in sub-urban schools. In the same vein this study disagrees with Yörük (2013) finding that there is difference in the perception of teachers working in rural and urban areas about violence.

\section{Conclusion}

Based on the findings of this study, it was concluded that violence is prevalent in early childhood classes due to forms like shouting, fighting, noise making, verbal abuse, hitting, slapping, beating and tearing of pupils' books. Moreover, violence in early childhood classes is prevalent in both rural and urban areas.

\section{Recommendations}

Parents and teachers should strive to be good role models. The home is the first crucial place where children are taught good morals and behaviour. If the home environment is adequate and non-violent instructions are given, children probably will be non-violent. The teacher, in the eyes of the children is never wrong and to that effect teachers should endeavour to model good behaviours before their children. Parents and teachers should demonstrate loving relationship to children. This will go a long way in trying to make them good citizens. Moreover, since violent behaviour is learnt, in the same way they can equally learn to be non violent if they are well cared for and loved.

Children learn by imitation and so parents should try to minimize conflicts in the home. The home is the first agent of socialization and so behaviours like fighting, shouting, quarrelling, physical and verbal abuse in the home should be avoided. Children should be well cultured to express their grievances in appropriate ways and not through violence.

Teachers and parents should support and guide children to imbibe civil ways of solving problems and effective ways of managing problematic situations. There is no doubt that good upbringing is one of the surest ways of avoiding crime in later life. Studies abound showing that high quality care in the first years of life can greatly reduce the risk that today's babies and toddlers will become tomorrow's violent adults. The implication is that parents, teachers and care givers should be very careful in the way they bring up children if there are going to be a violent free society.

Curriculum planners should endeavour to develop a curriculum that is relevant to young children in early childhood classes.

Teachers have to be very observant so that they can quickly identify children with violent tendencies and make pro-active arrangements for intervention.

\section{References}

African Child Policy Forum (2010). Childhood Scars in Africa; a retrospective study on violence against girls in Burkinafaso, Cameron, Democratic Republic of Congo, Nigeria and Senegal.

Bandura, A. (1977). Social Learning Theory, Eaglewood Cliffs, NJ: Prentice Hall.

Bartol, C. (2002). Criminal Behaviour. A Psychological Approach. Upper Saddle River, NJ: Prentice Hall.

Bush, L. (2001). White House Summit on Early Childhood Cognitive Development, in Teaching Our Youngest; A Guide for Preschool Teachers and Family Providers; Washington, DC.

Chukwu, J.O. (2003). Teachers Perception of Adolescents Violence in Primary School. The Educational Psychology, 1(163-171).

Effects of Emotional Abuse: How does Emotional abuse hurt? Retrieved from http:/wwwteach-throughlove.com/effects-emotionalabuse.html.

Espelage, D.L., Holt, M.K. and Henkel, R.R. (2003). Examination of Peer Group Contextual Effects on Aggression during Early Adolescence, Child Development 74, 205-220.

History learning site (2012). Classroom Violence. Retrieved from http://www.historylearning site.co. uk/classroom violence htm.

Kondrasuk, J.N., Greene, T., Waggoner, J., Edwards, K. and Nayak-Rhodes, A. (2005). Violence Affecting School Employees. Education 125, 638-647.

Lansford, J.E., Dodge, K.A., Petit, G.S., Bate, J.E., Crozier, J.A. (2002). A 12 year prospective study of the long term effects of early child physical maltreatment on psychological, behavioural and academic problems in adolescence. Archives of Pediatrics and Adolescent Medicine, 156:824-830 PMC free article (Pub Med).

Lansford, J.E., Miller-Johnson, S., Berlin, L.J., Dodge, K.A., Bates, J.E., Pettite, G.S. (2007). Early physical abuse and later violent delinquency: A prospective longitudinal study. Child Maltreat. 12(3): 233-245. doi:10.1177/1077559507301841 [PMC free article] 
[Pub Med].

Martin, D. (2013). Rise of Violent Primary Pupils: 40 Teachers attacked everyday-more than at secondary schools. Mail online publication 25 January 2013: retrieve 4/8/13.

Olweus, D. (1999). Sweden. In P.K. Smith, Y. Morita, J. Junger-Tas, D. Olweus, R. Catalano and P. Slee (Eds) The nature of school bullying: A cross national perspective London: Routledge Falmer.

Osanyin, F.A. (2001). Children's Education: Role of the 21st Century Woman. Journal of Women in Colleges of Education. 5, $22-23$.

Osanyin, F.A. (2012). An Augural Lecturer Series - Once upon a child in University of Lagos, Nigeria. University of Lagos Press.

Radojkovic, K. (2007). School Violence and Gender Perceptions of Pupils and School Staff in One School in Belgrade, Serbia. International Master of Science in Social Work.

RAND (2013). School Violence Prevalence, Fears and Prevention. Retrieved from http://www.rand.org/pubs/issue-papers/ JP/219index2.html.

Rutter, M., Giller, H. and Hagell, A. (1998). Antisocial Behaviour in Young People, Cambridge University Press, Cambridge.

The guardian.com. Monday 20 October 200812 26BST. Retrieved fromhttp://www.theguardian.com/ education/2008/oct/20/ knif-childschool-gatesheed. retrieved 2013.

Tremblay, R.E., Kurtz, L., Masse, L.C., Vitaro, F., Pihl, R.O. (1994). A Bimodal Intervention for Disruptive Kindergarten Boys; Its Impact through Mid-Adolescence. Unpublished manuscript. Montreal: University of Montreal, Research Unit on Children's Psycho-Social Maladjustment.

World Health Organization (WHO), (1996), WHO global consultation on violence and health. Violence: a public health priority, Geneva, (documentWHO/EHA/SPI.POA2).

Yarpuzlu, A., Karatas, B.G. and Kilic, E. (2010). An Investigation of School Violence and School Safety Based on Opinions of High School Students and Teachers in Ankara, Turkey. Ankara University Medical Sciences, 63 (4) DOI: 10.1501/ Tipfak_ 000000771.

Yörük, S. and Cankaya (2013). School Violence in Rural and Urban Centers of Turkey, International Journal of Social Science 6, (8). 